\title{
EXPERIMENTAL STUDIES REGARDING THE RISK-FREE WORK OF THE GANTRY CRANES
}

\author{
GHEORGHE N. RADU ${ }^{1}$, IOANA SONIA COMĂNESCU ${ }^{2 *}$

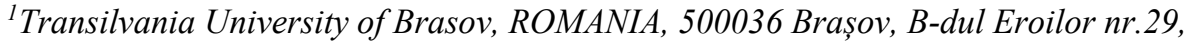 \\ Department of Mechanical Engineering \\ ${ }^{2}$ Transilvania University of Brasov, ROMANIA, 500036 Brașov, B-dul Eroilor nr.29, \\ Department of Engineering and Management in Food and Tourism
}

\begin{abstract}
The present paper sets that the prerequisite of a crane's failure (changes of the optimum technical state - risk of accidents occurrence), appear in their vibratory mark. The research has as main goal the increase of the work safety and the elimination of the risk of accidents. The tests had in view both the truss answer to dynamic forces in wind-bracings and the dynamic regime of the main beam.
\end{abstract}

Keywords: crane, work safety, risk, wind-bracing, failure, vibratory state

\section{TESTING EQUIPMENT}

Within the tests one used high performance equipment, signal conditioner, piezoelectric accelerometer, impact hammer, inductive transducer of linear stroke, resistance transducers for the measurement of the linear strokes, stress gauges and the SPIDER 8 system used for the numerical measurement of the mechanical quantities [1]. For the experimental data processing the Dinamica - Macara.tot software was used, achieved under Test Point.

The experimental tests were organized in three subchapters, where the dynamic loads were grouped as follows [2]:

- The structure's answer to the action of the dynamic forces in wind-bracings;

- The calculation of the main beam's deflection, in dynamic regime;

- The answer of the structure, in dynamic force regime, at the break of the lifted weight's driving cable.

In all three above mentioned cases of the performed experimental analysis, one follows a logical succession, which allows confidence and credibility (equipment, transducers, parameters which should be recorded, tests and conclusions).

Some results of research are presented below; these contain the used equipment, the way the transducers are placed, the users' interface of the SPIDER 8 system, the graphical representation of the recorded parameters, the tests results in graphical and tabular representation [3].

\subsection{Fracture risk areas}

In order to determine the state of stress and strain in the susceptible to fracture elements, a preliminary analysis of the potential failure areas was performed (Figure 1) [4].

\footnotetext{
${ }^{*}$ Corresponding author, email: ioanacom@unitbv.ro

(C) 2015 Alma Mater Publishing House
} 
- Main beam, profile I, in Si1;

- Main beam, right longitudinal tube in $\mathrm{Si} 2$ and $\mathrm{Si} 3$;

- Main beam, left longitudinal tube, Si3 and Si4;

- $\quad$ Forces in wind-bracings - T1 (N), T2 (N), T3 (N) and T4 (N).

The fitting manner of the stress gauges on the wind-bracings is shown in Figure 2 (TER system).

\subsection{Measurement equipment}

- Acquisition system SPIDER 8, 12 bits resolution;

- Force transducer U2B $10 \mathrm{kN}$, linearity $1 \%$;

- Force transducers for wind-bracing;

- Electric strain gauges LY 10/120 in half bridge for the stresses determination;

- Notebook IBM ThinkPad R 51.

The measurement system SPIDER 8, supplies as parameter the unit elongation $\varepsilon(\mu \mathrm{m} / \mathrm{m})$, in the area where the stresses gauges are applied $(\sigma=\mathrm{E} \cdot \varepsilon)$. In all the graphical representations, for the normal stress $\sigma(\mathrm{MPa})$, one used the symbol $\mathrm{Si}[5,6]$.

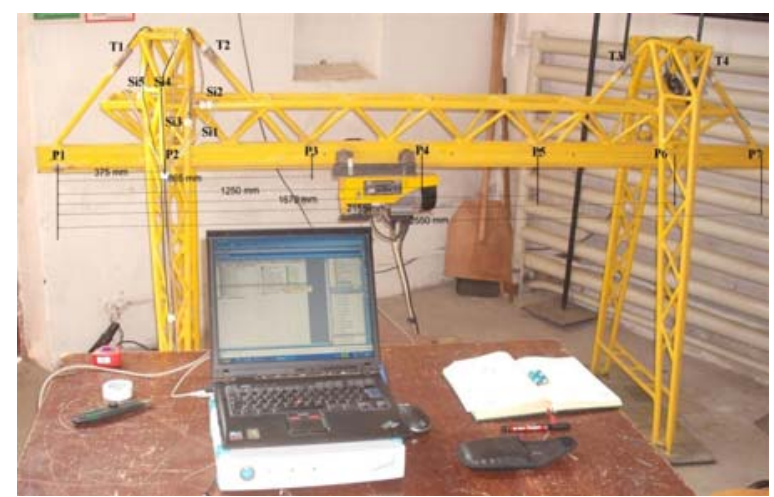

Fig. 1. Forces measurement in windbracings.

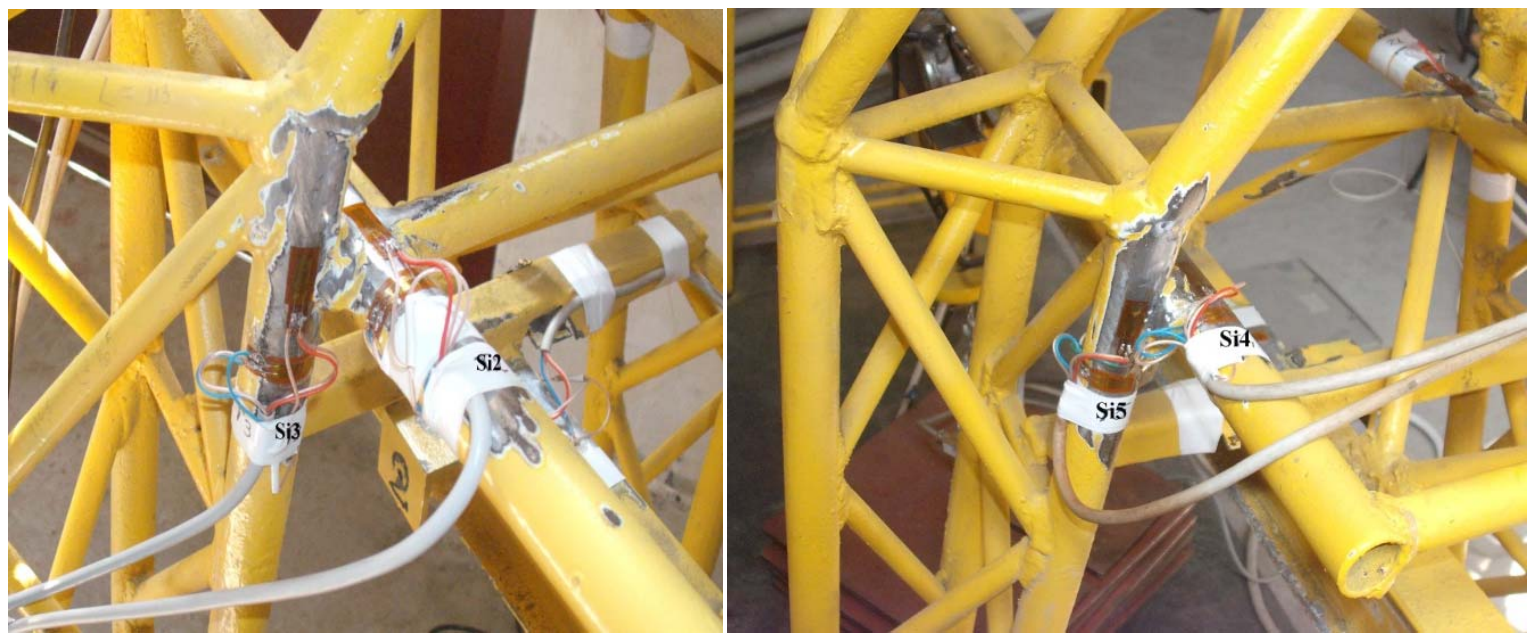

Fig. 2 Stresses determination in fracture susceptible elements [7].

Table 1. Stress in the fracture susceptible elements [7].

\begin{tabular}{|c|c|c|c|c|c|c|c|}
\hline $\begin{array}{c}\text { Load } \\
\text { Point }\end{array}$ & $\begin{array}{c}\text { Number of } \\
\text { weights }\end{array}$ & $\begin{array}{c}\text { Ft } \\
(\mathrm{N})\end{array}$ & $\begin{array}{c}\text { Si1 } \\
(\mathrm{MPa})\end{array}$ & $\begin{array}{c}\text { Si2 } \\
(\mathrm{MPa})\end{array}$ & $\begin{array}{c}\text { Si3 } \\
(\mathrm{MPa})\end{array}$ & $\begin{array}{c}\text { Si4 } \\
(\mathrm{MPa})\end{array}$ & $\begin{array}{c}\text { Si5 } \\
(\mathrm{MPa})\end{array}$ \\
\hline P1 & 8 & 1158.472 & -0.49697 & -0.06315 & -0.57373 & -1.3924 & 2.266022 \\
\hline P1 & 10 & 1444.092 & -0.56341 & -0.07319 & -0.65974 & -1.94479 & 2.61358 \\
\hline P2 & 8 & 1158.472 & 1.439609 & 0.283946 & 0.778276 & -2.12466 & -0.02303 \\
\hline P2 & 10 & 1444.092 & 1.897573 & 0.310765 & 1.055137 & -2.57573 & -0.12012 \\
\hline P3 & 8 & 1158.472 & 0.428675 & 0.774307 & 2.100624 & 0.228413 & -1.24899 \\
\hline
\end{tabular}




\begin{tabular}{|c|c|c|c|c|c|c|c|}
\hline P3 & 10 & 1444.092 & 0.541017 & 0.88938 & 2.606904 & 0.253396 & -1.55888 \\
\hline P4 & 8 & 1158.472 & 0.245665 & 0.217381 & 1.883697 & 0.985493 & -1.43623 \\
\hline P4 & 10 & 1444.092 & 0.29417 & 0.196337 & 2.31269 & 1.236637 & -1.8138 \\
\hline P5 & 8 & 1158.472 & 0.095057 & -0.29158 & 1.236273 & 1.100154 & -1.21218 \\
\hline P5 & 10 & 1444.092 & 0.109774 & -0.40445 & 1.510528 & 1.365756 & -1.52015 \\
\hline P6 & 8 & 1158.472 & -0.01616 & -0.1658 & 0.276117 & 0.357984 & -0.21576 \\
\hline P6 & 10 & 1444.092 & -0.02572 & -0.22585 & 0.337007 & 0.449007 & -0.30353 \\
\hline P7 & 8 & 1158.472 & -0.09182 & -0.33864 & 0.166251 & 0.694758 & -0.2772 \\
\hline P7 & 10 & 1444.092 & -0.13577 & -0.42991 & 0.173065 & 0.882781 & -0.37164 \\
\hline
\end{tabular}

Table 2. Magnitude of the forces acting in wind-bracing [7].

\begin{tabular}{|c|c|c|c|c|c|c|}
\hline $\begin{array}{c}\text { Load } \\
\text { Point }\end{array}$ & $\begin{array}{c}\text { Number of } \\
\text { weights }\end{array}$ & $\begin{array}{c}\mathrm{Ft} \\
(\mathrm{N})\end{array}$ & $\begin{array}{c}\mathrm{T} 1 \\
(\mathrm{~N})\end{array}$ & $\begin{array}{c}\mathrm{T} 2 \\
(\mathrm{~N})\end{array}$ & $\begin{array}{c}\mathrm{T} 3 \\
(\mathrm{~N})\end{array}$ & $\begin{array}{c}\mathrm{T} 4 \\
(\mathrm{~N})\end{array}$ \\
\hline 1 & 8 & 1158.472 & -714.217 & -480.649 & 2.820725 & 33.96707 \\
\hline 1 & 10 & 1444.092 & -829.093 & -555.193 & 2.986383 & 42.43365 \\
\hline 2 & 8 & 1156.937 & -152.968 & -131.48 & -18.0383 & 13.2324 \\
\hline 2 & 10 & 1442.996 & -176.812 & -162.686 & -23.7392 & 16.35647 \\
\hline 3 & 8 & 1157.135 & -50.0482 & -223.275 & -125.907 & 18.33355 \\
\hline 3 & 10 & 1443.607 & -62.0366 & -273.147 & -154.673 & 23.25374 \\
\hline 4 & 8 & 1156.203 & -7.04137 & -192.145 & -190.245 & -6.97096 \\
\hline 4 & 10 & 1444.921 & -7.64758 & -235.352 & -237.941 & -7.72406 \\
\hline 5 & 8 & 1156.942 & 18.11616 & -124.537 & -223.275 & -50.0482 \\
\hline 5 & 10 & 1443.583 & 22.978 & -152.99 & -273.147 & -62.0366 \\
\hline 6 & 8 & 1156.113 & 13.10138 & -17.7717 & -131.48 & -152.968 \\
\hline 6 & 10 & 1444.369 & 16.19452 & -23.3884 & -162.686 & -176.812 \\
\hline 7 & 8 & 1155.5 & 33.46509 & 2.792797 & -480.649 & -714.217 \\
\hline 7 & 10 & 1444.887 & 41.80655 & 2.956815 & -585.193 & -859.093 \\
\hline
\end{tabular}

Analyzing the achieved registrations (diagrams were also plotted), one mention that:

- The lift of the load is made with a high drop of the drive force, due to the inertia effect and to the cable's elasticity. For the lift of the weight of $1444 \mathrm{~N}$, the maximum value of the force is $2157 \mathrm{~N}$. The shock of the traction force acting upon the hook, leads to a similar drop of the forces in wind-bracings and of the stresses values in the crane's structure;

- The drive of the electric - mechanical brake produces a shock of the force on the driving cable with a maximum value of $1991 \mathrm{~N}$. In the driving cable, as well as in the crane's structure, a damped harmonic oscillation, on the natural frequency of the cable - load elastic system, is induced;

- From the analyzed frequencies spectrum, one emphasizes that the force acting on the hook presents a single resonance frequency, for $\mathrm{f}=9.15 \mathrm{~Hz}$, given by the elastic system mass driving cable [8];

- The wind-bracing forces show two resonance frequencies, an inner frequency at $\mathrm{f}=0.659 \mathrm{~Hz}$, given by the free horizontal oscillation of the mass connected to the crane's hook and the resonance frequency $\mathrm{f}=9.15 \mathrm{~Hz}$, presented above [9 - 12].

\subsection{Data recording}

During the tests were recorded the data regarding the motion of the crane's carriage, subjected to constant load (as shown in Figure 3) and the longitudinal and transversal balance of the crane's load (Figure 4).

One shifted the crane's carriage, loaded with 10 weights, equivalent to a load of $1444 \mathrm{~N}$, from point P1 to point P7, as shown in Figure 4. During the shift, the following parameters were recorded: $F(N)$ - the driving cable force, T1 (N) and T2 (N) - wind-bracing forces and stresses Si1 ... Si5 (MPa).

In order to establish the effect upon the wind-bracing forces and the corresponding value of the stresses, due to the longitudinal balance of the suspended load, a longitudinal balance of the $1444 \mathrm{~N}$ suspended load was induced. One proceeded in a similar manner for the transverse balance. The same registration, as presented above, was achieved (driving cable force, wind-bracing forces and stresses). Two of these registrations are presented below. 


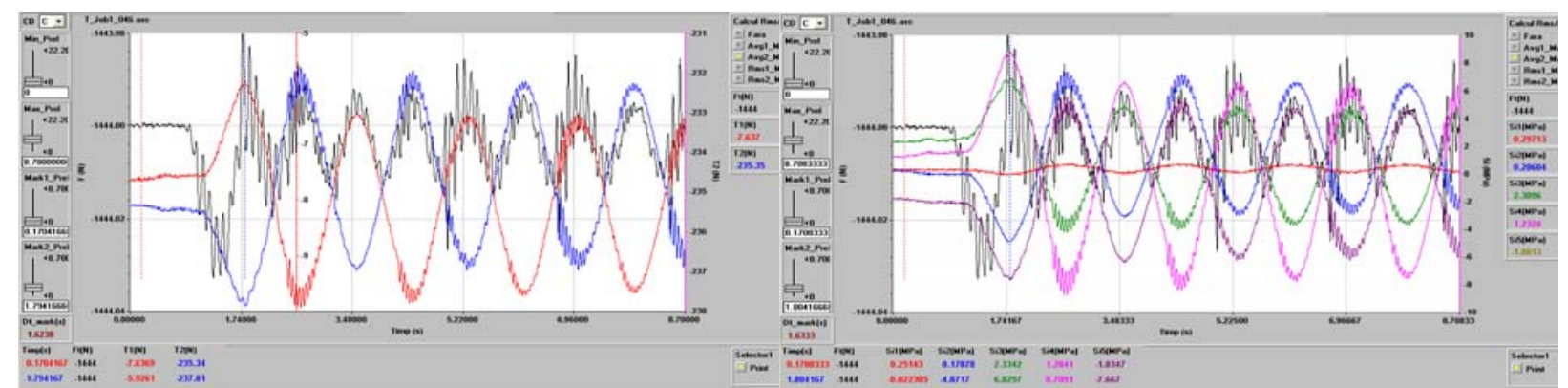

Fig. 3. Frequency spectrum of the force acting upon the hook.

Fig. 4. Force acting on the hook and stresses, load in P4.

One set the following conclusions:

- The forces acting in wind-bracings and the stresses in the susceptible to failure elements contain harmonic vibrations with the frequency of $0.58 \mathrm{~Hz}$, due to the horizontal oscillations' frequency of the cable suspended mass system;

- The effect of the suspended load's swing leads to an oscillatory motion, around the stabilized value, whose maximum values is approximately 1.06 times higher than the stabilized value;

- The load's balance has a strong negative effect upon the stresses of the susceptible to failure elements, loading to an oscillatory motion of high amplitude, which can touch the admissible stresses and even exceed them;

- The highest stresses yield when the swing load is applied in the point P1; this is the case when the welding connecting the main beam to the crane's supporting rods fails;

- The stresses due to the longitudinal balance of the suspended load are higher than those given by the transverse swing.

\subsection{Changing load. Deflection of the main beam}

In order to ensure an interaction between the main beam of the crane and the fixed body of the linear shift inductive transducers, a metallic frame which borders the crane was achieved (Figure 5).

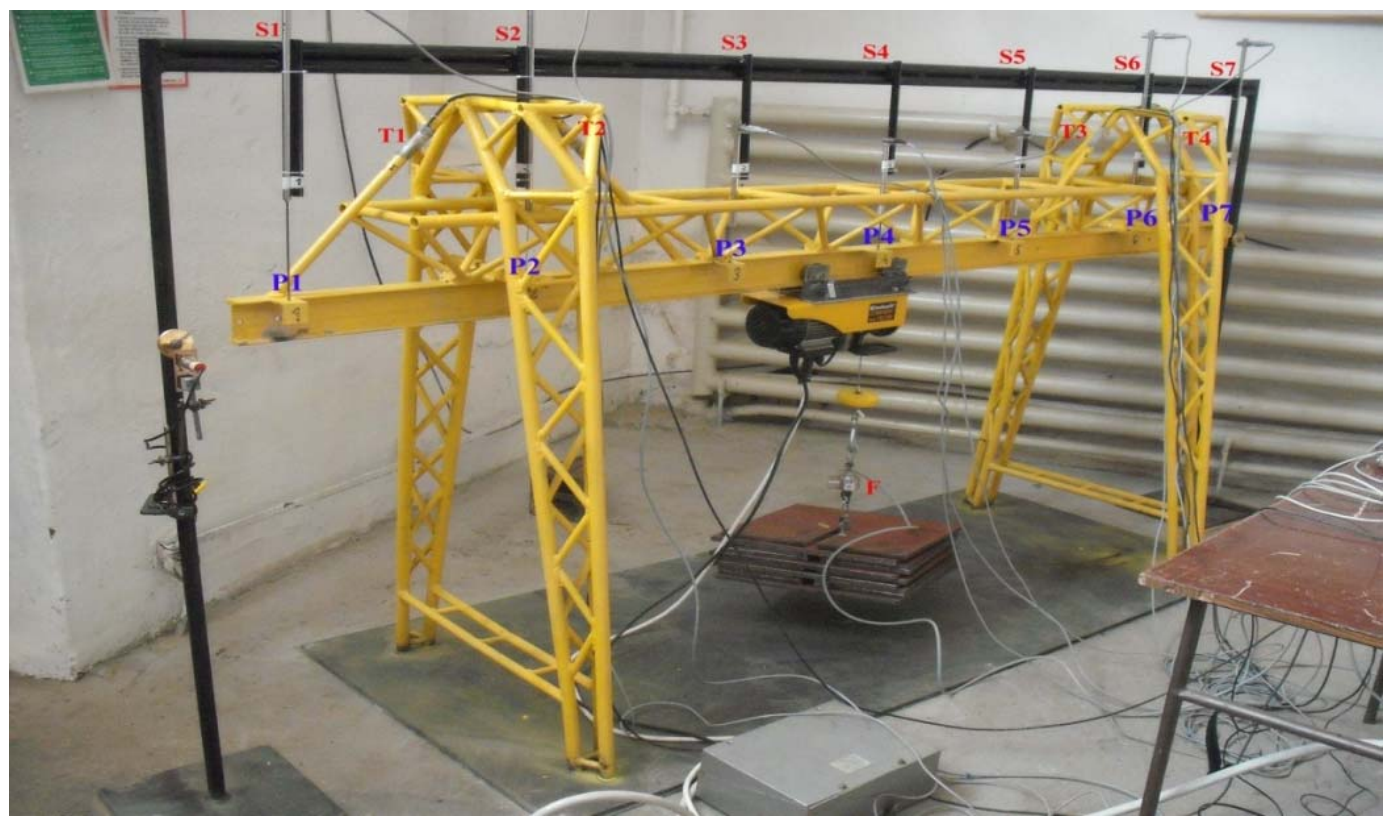

Fig. 5. Assembling scheme for the measurement of the deflections.

The inductive transducers were connected to the metallic frame and their moving rods were fixed connected to the cranes beam.

- Forces applied in P1, P2, ., P7 and the experimental determination of the main beam's deflection;

- $\quad$ The applied force was about 1444 [N], in P1, P2, .., P7 (Figure 6); 

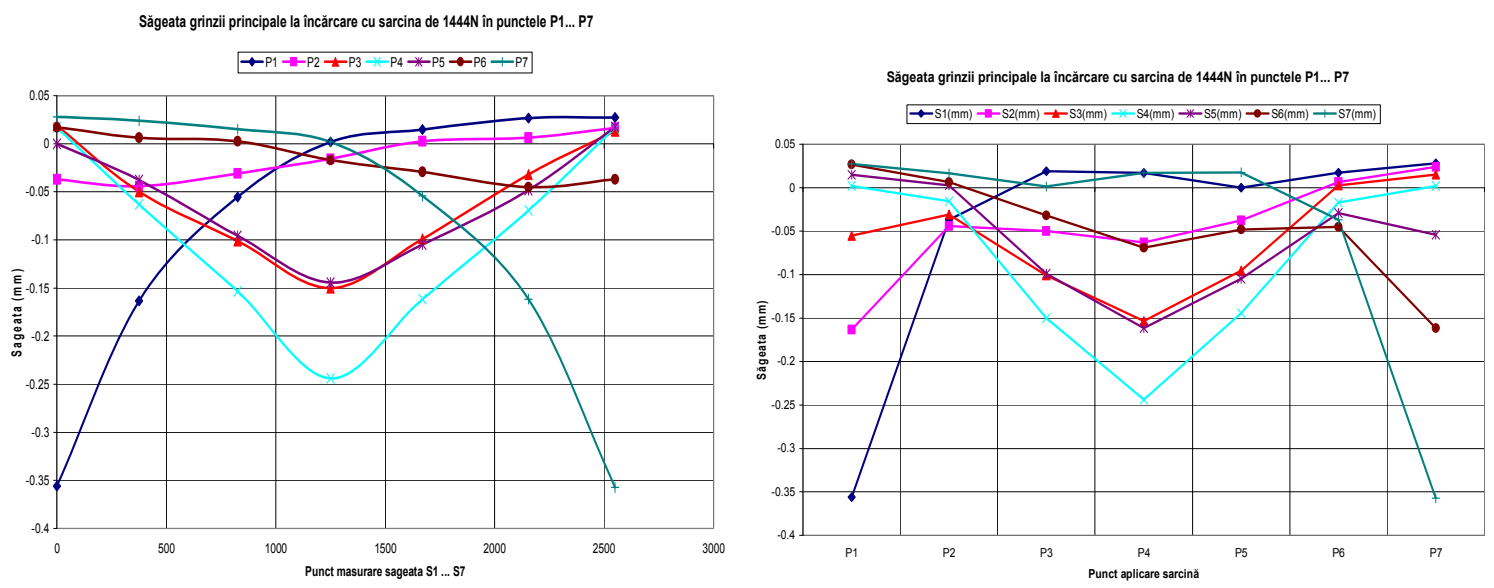

Fig. 6. The main beam's deflections, forces applied in P1, P2, .., P7

The recordings were performed in dynamic way of work; tests accomplished in two ways (Figure 6):

o Automatic scan in time or frequency fields;

o Animation at a stationary position of the slider.

\subsection{The break of the weight's lifting cable}

One performed tests in order to achieve the dynamic answer of the crane to varying loads given by the failure of the driving cable during the weight's uplift. In order to simulate experimentally the fracture of the cable, between the force transducer and the crane's hook, a steel wire of $\Phi=3 \mathrm{~mm}$ diameter was interposed, which fails at a force of about $1700 \mathrm{~N}$. The force transducer was fixed connected with the lifted load. The load was placed in point $\mathrm{P} 4$. The registrations were performed (Figure 7).

Analyzing the frequency answer of the accelerations in point P1 ... P7, one established that at the cable's rupture in point P4, the main beam's vibrations are large band frequencies, the frequencies spectrum of the vibratory answer laying in the $0 \ldots 400 \mathrm{~Hz}$ field (Figure 8).

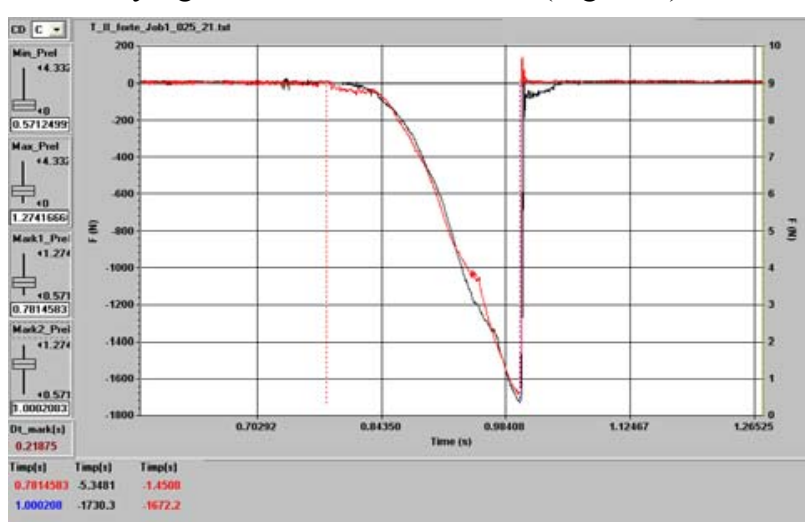

Fig. 7. Forces - Break of the cable.

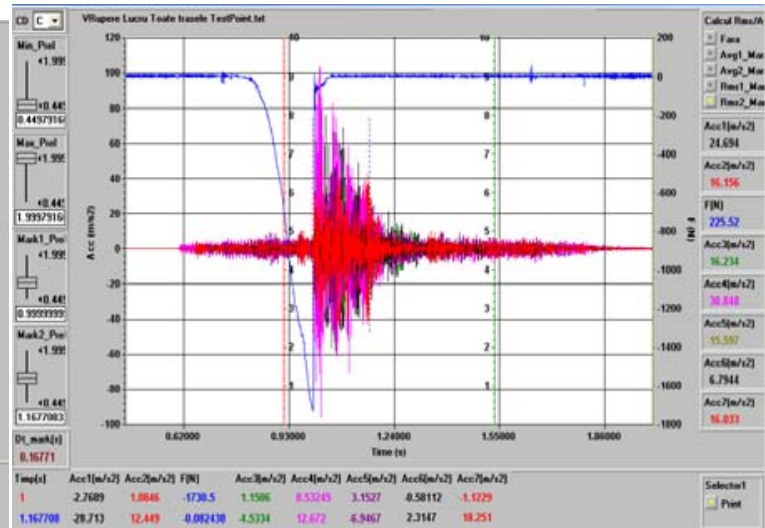

Fig. 8. Acceleration - break of the cable.

\subsection{Proposal concerning the modal experimental analysis for the elimination of accidents risk}

The Experimental Modal Analysis (EMA) [1] represents the method of achieving the mathematical model of a structure, based on the experimental data yielded through measurements of the structure brought, controlled vibratory state. The structure is excited in accurate established conditions and by ascertaining the evolution laws of the excitation and of the vibratory answer. One identifies a minimum number of parameters which describe the natural modes of vibrations: natural pulsation, damping constants, modal forms. The modal model allows the achievement of changes of the real structure and the theoretical valuation of the modified system's answer to the external or internal excitations' action, ascertaining the optimum changes in order to obtain a system with a desired vibratory answer. 
The answer is yielded in accelerations, displacements, bending moment or structure's stresses; these are defined in the points where the excitation or the vibratory answer was experimentally ascertained.

Routinely, the experimental modal analysis is applied together with the theoretical analysis with finite elements which works with a mathematical model likely to that of the experimental analysis. The experimental modal analysis requires high speed data acquisition techniques, high processing and storage capacity, an appropriate mathematical approach with discrete data series.

- One established that the modal analysis represents a very useful tool for the determination of eigen perturbation and modal forms.

- The identification of the modal forms is of great importance for the localization of some structural resonance in the field of the excitation frequencies (one achieves unwanted amplifications of the vibratory answer).

- For a given structure, the displacement of the resonance emphasizes the following issues:

o The fatigue of the material;

o Cracks in the supporting structure;

o Weakening of the assembling parts.

- The analysis of the modal forms emphasizes the weakness and the loosening or failure areas of the structure.

\subsection{Operational analysis}

For the given studied model one applied also the operational analysis through which one performed the determination of the mathematical model, based on the experimental data.

The measurement of the vibrations is accomplished in different points of the crane and the "vibratory behavior" is recorded as a moving picture of the geometrical model (both as time depending function and at different frequencies).

One established a "methodology" in terms of the operational analysis use; this one leads to the identification in real time of possibly geometrical and material defects. Through the structural vibratory analysis one discovers incipient defects. These can be kept under observation and one determines the optimum intervention period for the defect removal.

The following establishments concerning the process analysis are highly important:

- The excitations received by the crane in usual operating conditions (the crossing of the rollers over the crane - track's irregularities transmission gear, the working of the electric motor) are large band excitations, consistent in the high frequency field $150-400 \mathrm{~Hz}$;

- Through the comparative analysis of the natural pulsations yielded by the experimental modal analysis and the pulsations achieved through the operating analysis, one establishes that outcome excitations in usual working conditions can bring the structure to resonance in the high frequency field, yielding a great vibratory answer in the field of high frequencies $301.4 \mathrm{~Hz}, 373.7 \mathrm{~Hz}, 417.3 \mathrm{~Hz}$. One suggests as solution for the frequencies decrease, the achievement of a smooth crane - track and of roughness rollers.

\section{CONCLUSIONS. THE RISK FREE WORK OF THE GANTRY CRANES}

On basis of the present paper's approach, a comparative analysis of the theoretical studies and of the experimental tests was performed. The validation of the mathematical model used within the Finite Elements Method analysis (ABAQUS) is performed with help of the comparative analysis of the theoretically established deflections in points P1, P2, .., P7, at an applied load of $1444 \mathrm{~N}$ in points P1, P3 and P4, with the experimentally established deflections.

One established that, in the limit of an admissible error, the finite elements analysis can provide accurate information concerning the stresses and strains field. The finite elements pattern can be used for the dimensional analysis and for the constructive optimization of each crane type structure. On the accomplished model, changes of the constructive conception can be performed, loading to the structure optimization (Figure 9). 

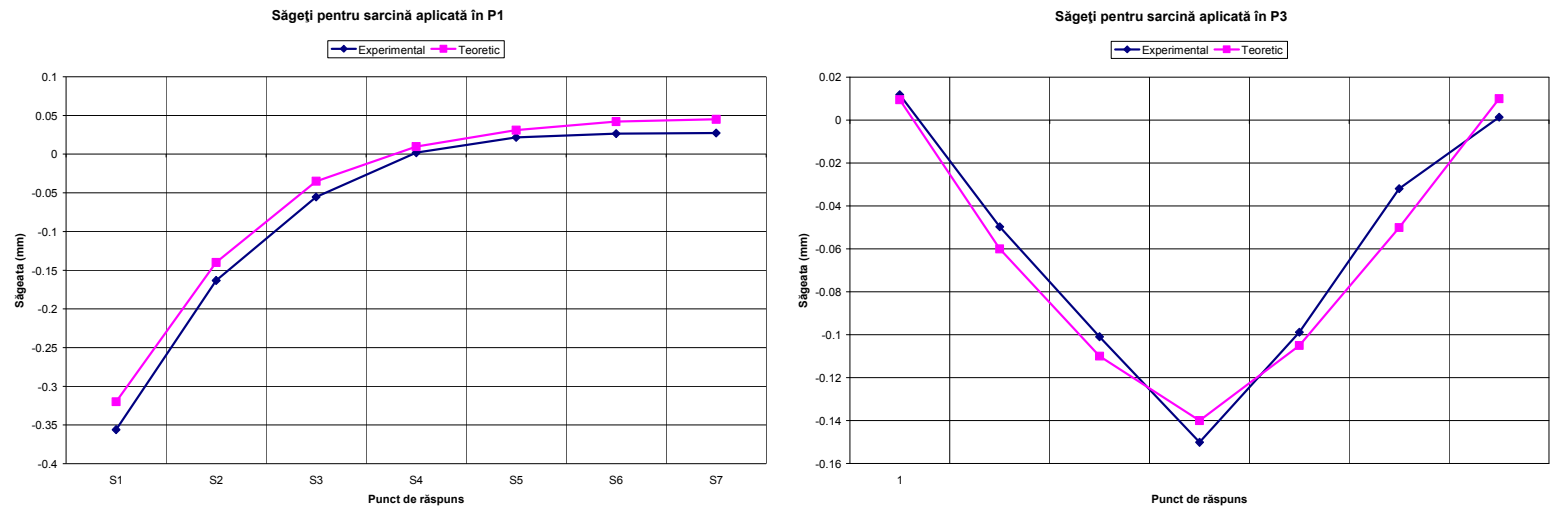

Fig. 9. Comparative analysis. Load in P1 and load in P3.

Beside the above presented conclusions at the end of each subchapter of the paper, one emphasizes general conclusions, too. These are presented as follows.

- All the performed theoretical and experimental research stand at the basis of the knowledge and determination of the work safety degree of the gantry cranes.

- One established a study methodology which can be generalized. The emphasized issue is valid for other cranes types, too.

- The experimental research program was extremely complex, the final conclusions being of great utility for the increase of the cranes work safety.

- In experimental structural analysis is mostly applied together with the FEM theoretical analysis; the FEM should use a mathematical model similar to that one yielded after the tests.

- $\quad$ Any structural model accomplished with FEM must be experimentally validated.

- The mixed mathematical models, theory and experiment, lead to accurate results.

- The frequency answer functions represent an efficient assessment method (referring to the dynamic answer of a mechanical system to imposed loads in several points of the structure).

- The optimization of a structure may be performed only through theoretical studies and experimental tests.

- For the analytical determination of the structure's answer at imposed excitations, the experimental determination of the matrix of frequency answer functions is required.

- The studied structure is brought to a controlled vibratory state, one performs measurements and the final mathematical model of the structure is finally achieved.

- The functions of the frequency answer are uniquely associated to the real system.

- The identification of the natural vibrations is highly important; thus, one achieves the location of some structural resonances and the identification of weakness of the loosening and failure areas of the structure.

- The present paper proposes also the use of the experimental modal analysis. This method completes the already existing procedure and leads to the avoidance of accidents risks

The following succession is suggested:

- $\quad$ The structure is excited under known conditions;

- $\quad$ One determines the excitation evolution laws;

- $\quad$ The vibratory answer is recorded;

- $\quad$ Some parameters which describe the natural vibrations modes are recorded;

- A theoretical evaluation of the structure's answer to different excitation conditions (load lifting, carriage displacement, transverse and longitudinal balance) is accomplished.

One states that the accomplished modal model allows the achievement of changes of the real structure, and the theoretical evaluation of the modified system's answer.

The experimental modal analysis benefits of real time acquisitions techniques of the measurements. The method may successfully complete the already existing procedures for the gantry crane work analysis, thus, the accident risks is cancelled. 


\section{REFERENCES}

[1] Manea, I., Analiza modala experimentala, Editura Universitaria Craiova, 2006.

[2] Radu, N. Gh., Comanescu, I.S., Popescu, M., The Study of the Behavior under static and dynamic Load of the Main Beam (profile "I") of a Portal Crane, Part I - The State of Deformation of the Main Beam under static Load, Part II - The state of deformation of the main beam in the "animation" working manner, COMEC 2011, Brasov, 1991.

[3] Radu, N. Gh., Comanescu, I.S., Popescu, M., The Behavior under Load of the Portal Gantry Crane, referring to strength, stiffness and stability, Part I - Theoretical consideration, Part II - The Stresses and Deformations results by FEM analysis - ABAQUS, Part III - Experimental determinations of the field of stresses and strains, The $9^{\text {th }}$ International Conference OPROTEH 2011, Bacau, Romania.

[4] Radu, N.Gh., Rezistenta materialelor si elemente de teoria elasticitatii, vol. I (2002) si vol. II (2002), Ed. Universitatii Transilvania din Brasov.

[5] Radu, N.Gh., Capitole special de rezistenta materialelor, Editura TEHNICA INFO. Chisinau, 2007.

[6] Vasilescu, Al., Praisler, G., Similitudinea sistemelor elastic, Editura Academiei Romane, Bucuresti, 1974.

[7] Popescu, M., Studiul macaralelor portal, Teza de doctorat, 2010.

[8] Nastasescu, V., Stefan, A., Lupuiu, C., Analiza neliniara a structurilor mecanice prin metoda elementelor finite, Editura Academiei Tehnice Militare, Bucuresti, 2002.

[9] Gioncu, V., Ivan, M., Bazele calculului structurilor la stabilitate, Editura Facla, Timisoara, 1983.

[10] Spinacovski, A.O., Rudenko, N.F., Masini de ridicat si transportat, Editura Tehnica, Bucuresti, 1973.

[11] Vita, I., Sarbu, L., Nuteanu, T., Alexandru, C., Masini de ridicat in constructii, Editura Tehnica, Bucuresti, 1989.

[12] ***SR ISO***Instalatii de ridicat. Organe de comanda, Reguli si metode de incercare, Cabine, Clasificare. 